\title{
Feral cats threaten the outstanding endemic fauna of the New Caledonia biodiversity hotspot
}

\author{
Pauline Palmas $^{\mathrm{a}, \mathrm{b}, *}$, Hervé Jourdan ${ }^{\mathrm{a}}$, Fredéric Rigault ${ }^{\mathrm{a}}$, Léo Debar ${ }^{\mathrm{a}}$, Hélène De Meringo ${ }^{\mathrm{c}}$, \\ Edouard Bourguet $^{\mathrm{a}}$, Mathieu Mathivet ${ }^{\mathrm{a}}$, Matthias Lee ${ }^{\mathrm{a}}$, Rachelle Adjouhgniope ${ }^{\mathrm{a}}$, Yves Papillon ${ }^{\mathrm{a}}$, \\ Elsa Bonnaud ${ }^{\mathrm{b}}$, Eric Vidal ${ }^{\mathrm{a}}$ \\ ${ }^{a}$ Institut Méditerranéen de Biodiversité et d'Ecologie marine et continentale (IMBE), Aix Marseille Université, CNRS, IRD, Avignon Université, Centre IRD de Nouméa, \\ BPA5, 98848 Nouméa cedex, Nouvelle-Calédonie \\ ${ }^{\mathrm{b}}$ Ecologie Systématique Evolution, Université Paris-Sud, CNRS, AgroParisTech, Université Paris-Saclay, Orsay, France \\ c Institut Méditerranéen de Biodiversité et d'Écologie marine et continentale (IMBE), Aix Marseille Université, CNRS, IRD, Avignon Université, Europôle de l'Arbois, BP 80, \\ 13545 Aix-en-Provence, France
}

\section{A R T I C L E I N F O}

\section{Keywords:}

Felis catus

Invasive predator

Diet

Threatened species

Island ecosystems

Feeding habits

\begin{abstract}
A B S T R A C T
Feral cats (Felis catus) are one of the most successful and harmful invasive predator species, leading to dramatic loss of biodiversity across the globe. Our study assessed feral cat predation in a major biodiversity hotspot: the New Caledonian archipelago. We focused on the consequences of this predation for the outstanding endemic fauna found throughout the rich range of New Caledonian natural habitats. We analyzed $>5300$ cat scats sampled from 14 selected sites representing the 4 main natural habitats, with 4 to 6 sampling sessions per year over $>4$ years per habitat. Our study reveals previously unreported patterns of cat predation on both alien and endemic species. Throughout the archipelago, cats prey strongly upon squamates, flying foxes and petrels. Feral cat prey included at least 44 native vertebrate species, 20 of which are IUCN Red-listed threatened species. This study adds some $44.4 \%$ to the number of IUCN threatened species vulnerable to and preyed upon by feral cats on the world's islands. New Caledonia, while it represents only $0.12 \%$ of the total area of islands worldwide (Australia included), hosts $30.8 \%$ of IUCN threatened species known to be predated by feral cats. This study recommends prioritizing management and conservation strategies by focusing actions on maquis mosaic and humid forest habitats, where feral cats pose the greatest threat. To limit the impact of feral cats, we recommend conducting targeted management actions on sites key to threatened species conservation, and preventing arrival or promoting eradication on islets.
\end{abstract}

\section{Introduction}

Biological invasions are one of the main threats to world biodiversity, especially on islands. Invasive species are considered the primary cause of island biodiversity loss (Clavero and Garcia-Berthou, 2005; Sax and Gaines, 2008; Tershy et al., 2015). Alien mammal predators have been responsible for most species extinctions on islands worldwide (Blackburn et al., 2004; Doherty et al., 2016b). The domestic cat (Felis catus), is one of the most widespread introduced predators on islands (Courchamp et al., 2003; Medina et al., 2011). Its life history traits, early domestication with companion animal status, and value as a rodent catcher have promoted its extensive, human-mediated dispersal on islands (e.g. Driscoll et al., 2007; Hu et al., 2014). In addition, introduced cats' high reproductive success, rapid geographical spread and generalist predator behavior particularly threaten native fauna, especially in their feral form (e.g. Medina et al., 2011; Turner and Bateson, 2014). Of invasive mammalian predators, feral cats have proven to be the most damaging species for insular fauna. They currently threaten 430 different species (birds, mammals and reptiles) with extinction and are implicated in the recent extinction of 63 species (40 bird, 21 mammal and 2 reptile species), i.e. $26 \%$ of recent extinctions (Doherty et al., 2016b). Furthermore, Doherty et al. (2015a) for Australia and adjacent islands and Bonnaud et al. (2011) for the rest of the world's islands, listed 16 and 29 IUCN Red-listed threatened vertebrate species respectively, in the diets of feral cats. Strong variations exist in the feral cat diet, mainly explained by biogeographic and bioclimatic factors, along with prey availability (Bonnaud et al., 2011; Doherty et al., 2015a; Medina et al., 2011). Bonnaud et al. (2011) and Doherty

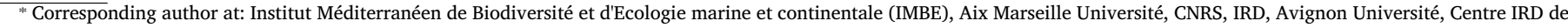
Nouméa, BPA5, 98848 Nouméa cedex, Nouvelle-Calédonie.

E-mail address: pauline.palmas@ird.fr (P. Palmas).
} 
et al. (2015a) showed that feral cats on islands feed on a wide range of prey, including medium-sized and small vertebrates (birds, reptiles, marsupials, rodents, bats, frogs, fish, and both medium-sized and large exotic mammals) and invertebrates (Bonnaud et al., 2015; Hilmer et al., 2010; Turner and Bateson, 2014). Introduced mammals (rodents and lagomorphs) generally constitute staple prey that can facilitate the establishment and expansion of abundant feral cat populations, indirectly increasing predation risk for native species through a so-called "hyperpredation" mechanism (e.g. Courchamp et al., 1999; Ringler et al., 2015).

Located in the southwest Pacific Ocean, the New Caledonian archipelago is typical of sites that facilitate invasion. Originally, native apex predators only included squamate and bird taxa. The early introduction of the Polynesian rat (Rattus exulans) by the first Austronesian settlers, followed in around 1860 by the European introduction of other commensal rodents (particularly the Black rat Rattus rattus), provided ideal conditions for the establishment and rapid spread of feral cat populations (e.g. Doherty et al., 2015b). In the biodiversity hotspot of New Caledonia, terrestrial species richness and endemism rates reach outstanding levels (Mittermeier et al., 2011; Myers et al., 2000). It is notable that 98 of the 108 terrestrial squamates, 6 of the 9 native mammals (bats) and 24 of the 111 nesting birds are strictly endemic, some of them micro-endemic (Barré et al., 2009; Bauer et al., 2012a, 2012b; Hand and Grant-mackie, 2011; Sadlier et al., 2012, 2013, 2014a, 2014b, 2014c, 2014d; Whitaker and Sadlier, 2011).

Cats were introduced around 1860 (Pascal et al., 2006) and can now regularly be observed in a wide range of habitats throughout the archipelago, even in its most remote and elevated areas. However, several papers have pointed out the complete absence of feral cat studies in this hotspot, stressing the urgent need to investigate this potentially important conservation topic (Bonnaud et al., 2011; Nogales et al., 2013). This paper addresses a number of issues pertaining to the feeding ecology of feral cats and their impacts on the exceptional terrestrial fauna of the New Caledonian biodiversity hotspot. To assess feral cat diets, we conducted intensive 6-year feral cat scat sampling at the scale of the archipelago. This enabled us to explore the composition of the feral cat diet and to determine the relative importance of different prey items according to habitat type (4 main habitat categories) and season ( 2 categories). Particular attention was paid to identifying prey taxa, so as to better understand the nature and the extent of feral cat impact at the different study sites and in the different habitats. We especially focused on IUCN Red-listed threatened species that are prey to the feral cat, in order to provide suitable evidence-based management and conservation recommendations concerning this invasive alien top-level predator.

\section{Materials and methods}

\subsection{Study sites and sampled habitats}

Of the 36 biodiversity hotspots, New Caledonia is the smallest formed of a single archipelago (Mittermeier et al., 2011). This hotspot $\left(21^{\circ} 30^{\prime} \mathrm{S}, 165^{\circ} 30^{\prime} \mathrm{E}\right)$ with 270000 inhabitants, located in the southwest Pacific Ocean $1210 \mathrm{~km}$ east of Australia, covers $18,576 \mathrm{~km}^{2}$ and is composed of a main island $\left(16,664 \mathrm{~km}^{2}\right)$ and various satellite islands (Lifou, Maré, Ouvéa, Isles of Pines, Art, Pott, Tiga) (Dubois et al., 1973). The New Caledonia archipelago is, characterized by a large variety of habitats with a mountainous topography and marked climatic and geological contrasts (Isnard et al., 2016). Each habitat harbors very unique species assemblages, and rates of endemism for flora and fauna are especially high because of its geographical isolation and particular ultramafic soils (Grandcolas et al., 2008; Isnard et al., 2016).

The climate is subtropical with average annual temperature varying between $21.9^{\circ} \mathrm{C}$ and $24.1{ }^{\circ} \mathrm{C}$. Due to dominant winds from the southeast, the eastern coast is wet, with $2500-4000 \mathrm{~mm}$ of rain per annum, while the western coast is drier, with $1200 \mathrm{~mm}$ of rain per annum. There are two main seasons: a hot, wet season (November-April), a cold, dry season (May-October), defined by calculating the average of monthly precipitations recorded by 50 stations between 1971 and 2000 (Wet $>120 \mathrm{~mm} /$ month; Dry $<120 \mathrm{~mm} /$ month) and the average of monthly temperatures at 5 stations between 1980 and 2010 (Hot $>23^{\circ} \mathrm{C}$; Cold $<23^{\circ} \mathrm{C}$ ) (Meteo France). Due to its mountainous topography, the archipelago has a wide range of ecosystems (ranging in altitude from $1 \mathrm{~m}$ a.s.l. to $1625 \mathrm{~m}$ a.s.l.).

These climatic contrasts lead to markedly different habitats, each characterized by typical vegetation types. We thus considered 4 major habitats representing a wide range of climatic conditions and vegetation. The "Dry forest" is composed of sclerophylous and mesic forest on sedimentary rocks. The "Humid forest" is composed of rain forest on metamorphic rocks. The "Maquis mosaic" is composed of maquis shrubland and rainforest on serpentine soils (A.1). The "Limestone forest" is composed of rainforest on calcareous soils (Isnard et al., 2016).

\subsection{Cat diet study}

\subsubsection{Sampling design and sampling effort}

Feral cat diet was studied through scat analysis (e.g. Bonnaud et al., 2007). We collected feral cat scats from 14 different areas in the 4 main types of habitat listed above, between 2011 and 2016 (Fig. 1, Table 1). Scats were collected along paths and rural roads used by cats (Turner and Bateson, 2014; Recio et al., 2015). Scats from each study site (Fig. 1) were collected along the same selected paths in all sampling sessions (3-6 sampling sessions per year; 3-14 sampling sessions per site). Because all scats found were collected, it was assumed that each sampling set reliably represented the feral cats' diet between two successive sampling sessions. During the 6-year sampling period, 5356 feral cat scats were collected across all the habitats and study sites. Cumulatively, this represents a total of $2435 \mathrm{~km}$-sessions (mean effort \pm Standard Deviation: $608.8 \pm 751.0 \mathrm{~km}$-sessions per habitat), with a total sampling length of $267 \mathrm{~km}$ (mean sampling length $66.7 \pm 64.7 \mathrm{~km}$ per habitat). An average of $1339 \pm 1327$ scat samples were collected from the different habitats, with a mean of $2.7 \pm 1.3$ scats found per $\mathrm{km}$ per session. Thus, despite the uneven sampling effort in the different habitats and sites, our sampling can be considered robust and significant $(\mathrm{n}>100$ for all habitats and $\mathrm{n}>100$ for most sites) (Bonnaud et al., 2011). Each cat scat was georeferenced, stored in individual Ziploc bags, and frozen until it was analyzed.

\subsubsection{Determination of prey remains}

Scats were washed under water over a $0.5-\mathrm{mm}$ sieve to sort prey items (hair, bone fragments, teeth, squamate jaws and scales, bird feathers, bat claws, and arthropod chitin fragments). The prey items were examined under binocular microscope, compared to reference material and assigned to one of the eight following prey categories: (1) introduced rodents, (2) bats, (3) birds, (4) squamates, (5) arthropods, (6) fishes, (7) plant materials and (8) anthropogenic refuse (Bonnaud et al., 2007). Differential degradation of prey remains during the digestion process can cause the loss of some diagnostic characteristics (i.e. shape, size, color), leading to differing levels of prey group identification (Zarzoso-lacoste et al., 2016). To deal with these identification difficulties, we systematically used a large reference collection that proved particularly useful for squamates (scale patterns, jaws, head bones), flying foxes (hair, claws, teeth) and seabirds (feathers, claws, beaks) (A.2).

Based on scat analysis, two different diet indexes were used: (i) Frequency of Occurrence (\%FO), the occurrence of each type of prey per scat (Bonnaud et al., 2007); and (ii) Minimum number of individual prey for squamates. To determine feral cat predation on each prey group, we examined each group's occurrence in the cat diet according 


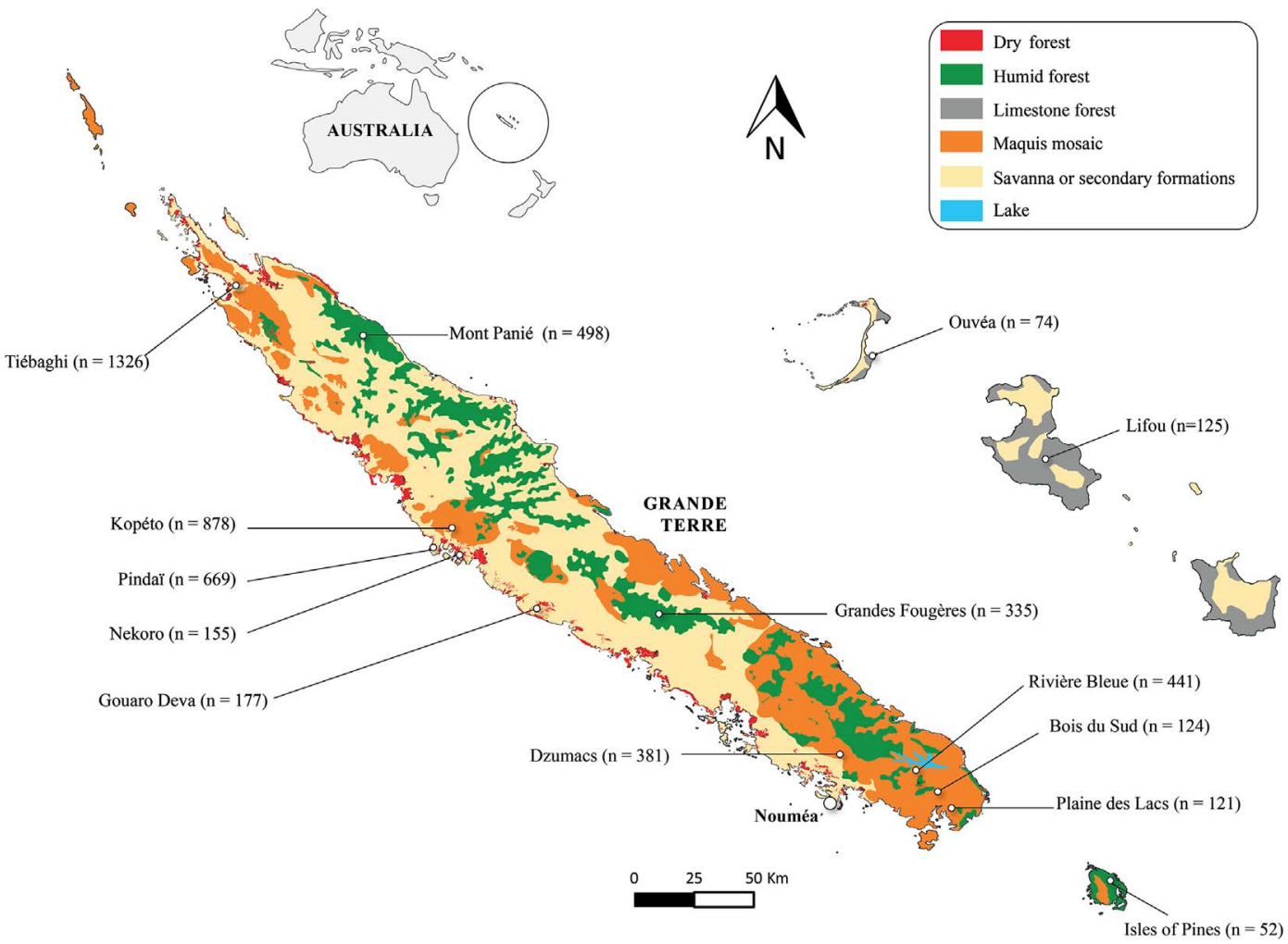

Fig. 1. Location of the feral cat diet study sites within the New Caledonia archipelago ( $\mathrm{n}=$ number of scats collected and analyzed).

to habitat and season, assessing their conservation status with reference to the IUCN, 2016-3 Red List of Threatened Species (IUCN, 2016).

\subsection{Statistical analyses}

All statistical analyses were conducted with R 3.0.3 software ( $R$ Core Team, 2014) using "pROC" (Fawcett, 2006). Generalized Linear Models (GLM) were run to test the effect of habitats and seasons on (i) presence of each prey in cat diet (ii) presence of threatened species in cat diet. We used individual scats as the experimental unit. A binomial distribution was used for (i) and (ii) [in R: glm (response $\sim$ habitats * seasons), family $=$ binomial (link $=$ "cloglog")]. Significant relationships were inferred at $\alpha=0.05$. The area under the ROC-curve plot (AUC) was used to assess the accuracy of model predictions (Fielding and Bell, 1997). AUC values usually range from 0.5 (random) to 1.0 (perfect) prediction. We did not include site and sessions as factors in the GLMs since our aim was to understand how cat diet varies according to habitat type and season, rather than between years or within habitat types.

\section{Results}

\subsection{Overall patterns of feral cat diet in the New Caledonian biodiversity hotspot}

Trophic analysis of the 5356 scats showed that feral cats preyed most strongly upon introduced rodents (FO $=78.2 \%$ ) (Table 2 ), followed by squamates (42.8\%) and arthropods (35.2\%, mainly insects). Bird and bat remains were found in $18.0 \%$ and $2.7 \%$ of scats respectively, while fish remains were found in $1.9 \%$ of scats. Traces of anthropogenic refuse were found in only $2.9 \%$ of scats. $30.7 \%$ of scats were exclusively composed of rodent remains, while $21.8 \%$ contained

Table 1

Sampling details.

\begin{tabular}{|c|c|c|c|c|c|c|c|}
\hline Habitat types & Study sites & Altitude range $(\mathrm{m})$ & $\begin{array}{l}\mathrm{N} \text { cat scats/ } \\
\text { habitat }\end{array}$ & $\begin{array}{l}\text { Path length/habitat } \\
(\mathrm{km})\end{array}$ & $\begin{array}{l}\text { Sampling effort (km- } \\
\text { session) }\end{array}$ & $\begin{array}{l}\text { N scats } / \mathrm{km} / \\
\text { session }\end{array}$ & Number of sessions \\
\hline \multirow[t]{3}{*}{ Dry forest } & Gouaro Deva & $1-35$ & 1001 & 45.7 & 300.3 & 3.77 & 3 \\
\hline & Nekoro & $1-120$ & & & & & 4 \\
\hline & Pindaï & $1-70$ & & & & & 10 \\
\hline \multirow[t]{2}{*}{ Humid forest } & Grandes Fougères & $340-680$ & 833 & 20.9 & 205.8 & 4.10 & 9 \\
\hline & Mont Panié & $560-1625$ & & & & & 11 \\
\hline \multirow[t]{3}{*}{ Limestone forest } & Iles of Pines & $1-260$ & 251 & 37.7 & 196.0 & 1.40 & 4 \\
\hline & Lifou & $3-55$ & & & & & 5 \\
\hline & Ouvéa & $1-30$ & & & & & 6 \\
\hline \multirow[t]{7}{*}{ Maquis mosaic } & Bois du Sud & $150-200$ & 3271 & 162.5 & 1733.0 & 2.27 & 7 \\
\hline & Dzumac & $200-980$ & & & & & 11 \\
\hline & Kopéto & $440-1000$ & & & & & 13 \\
\hline & Plaine des lacs & $200-600$ & & & & & 7 \\
\hline & Rivière Bleue & $145-220$ & & & & & 9 \\
\hline & Tiébaghi & $8-550$ & & & & & 14 \\
\hline & Total & $1-1625$ & 5356 & 267 & 2435 & 2.88 & 113 \\
\hline
\end{tabular}




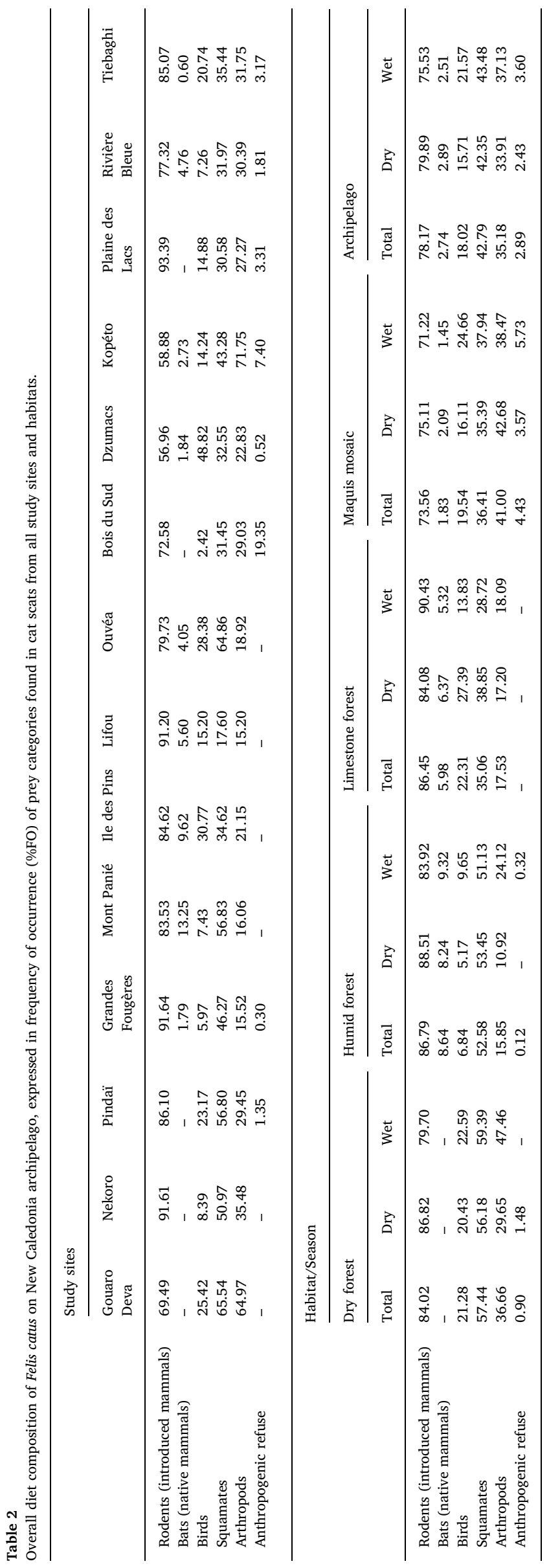

no rodent remains (Fig. 2).

For example, in the limestone forest $40.2 \%$ of scats contained only rodent remains, $46.2 \%$ contained both rodent remains and native prey remains, while $13.5 \%$ contained only native prey remains (Fig. 2). In the maquis mosaic $30.2 \%$ of scats contained only rodent remains, $43.3 \%$ contained both rodent remains and native prey remains, while $26.4 \%$ contained only native prey remains (Fig. 2).

\subsection{Patterns of predation on different prey types}

The GLM describing prey occurrence in cat diet correctly predicted presence and absence (AUC ranging from 0.59 for squamates to 0.78 for arthropods) (Table A.2).

Introduced rodents were the predominant prey category found in the feral cat diet for all habitats and all seasons (Table 2, Table A.1). The effect of habitat was significant $(P<0.001)$ on introduced rodent FO, the highest FO for rodents being found in humid forests $(86.8 \%)$ and the lowest FO being found in maquis mosaic (73.6\%). The seasonal effect was significant $(\mathrm{P}<0.001)$, with higher frequency found for the dry season (FO $=79.9 \%$ ) (Table A.2).

Bat remains were found in cat scats in all habitats except the dry forest. The effect of habitat on occurrence of bat remains was significant ( $\mathrm{P}<0.001)$, the highest FO being found in humid forests $(8.6 \%)$ and the lowest being found in dry forest and maquis mosaic $(0 \%$ and 1.8 respectively). There was no effect of season on the FO of bats in cat diets $(\mathrm{P}=0.551)$. Pteropodids were predominant among bat remains, composing $95.2 \%$ of the scats containing remains of identified bats. Three different Pteropodidae prey were identified: the Ornate Flying Fox (Pteropus ornatus), the Pacific Flying Fox (Pteropus tonganus) and the New Caledonia Flying Fox (Pteropus vetulus), found respectively in $1.53 \%, 0.28 \%$ and $0.04 \%$ of the total scats. Microchiroptera remains were exclusively found in maquis mosaic and in $<0.06 \%$ of the total scats $(2.2 \%$ of the scats that contained bat remains).

Birds were consumed in all habitats. The effect of habitat $(\mathrm{P}<0.001)$ on bird occurrence in the cat diet was significant, the highest FO being found in limestone forest $(22.3 \%)$ and the lowest FO being found in the humid forest $(6.8 \%)$. There was an effect of habitat*season $(P<0.001)$. The effect of season $(P<0.001)$ was significant, with higher frequency of birds found for the wet season (21.6\%). Procellariiformes were the predominant bird prey (mean FO: $7.5 \%$, highest FO in maquis mosaic and dry forest with $9.8 \%, 6.8 \%$ respectively). Three different species were found: the Tahiti petrel (Pseudobulweria rostrata), the Wedge-tailed shearwater (Ardenna pacifica), and Gould's petrel (Pterodroma leucoptera), respectively in $3.4 \%$, $1.4 \%$ and $0.2 \%$ of scats. Moreover, $2.5 \%$ of scat samples contained Procellariiforme remains that could not be distinguished as either Tahiti or Gould's petrel. Passeriformes were identified in cat scats from all four habitats (mean FO $=1.9 \%$ ), while Psittaciformes were found exclusively in limestone forest $(0.8 \%, \mathrm{n}=2)$ and maquis mosaic study sites $(0.06 \%, \mathrm{n}=2)$. Surprisingly, no remains of either the adult or young Kagu (Rhynochetus jubatus), a flightless New Caledonian endemic bird, were found anywhere including in the 776 feral cat scats collected within the two major bastions of this species ("Grandes Fougères" and "Rivière Bleue" areas).

Squamates were the second most predominant prey category found in cat scats for all habitats and all sampling periods. The effect of habitat $(\mathrm{P}<0.001)$ was significant, the highest FO being found in the dry and humid forests ( $57.4 \%$ and $52.6 \%$ respectively), and the lowest FO being found in limestone forest (35.1\%). There was no effect of season on the FO of squamates in cat diets $(P=0.327)$. Skinks were predominant among squamate remains in cat scats from all habitats and all sampling periods. The highest FO was found in the dry and humid forests $(53.2 \%$ and $48 \%$ respectively). Our study sites host 45 different skink species, 33 of which were present in our scat samples (Fig. 3). Feral cats preyed upon a larger number of skink species in the maquis mosaic (23 out of 33 species present) and humid forests (16 out of 18 species present). 


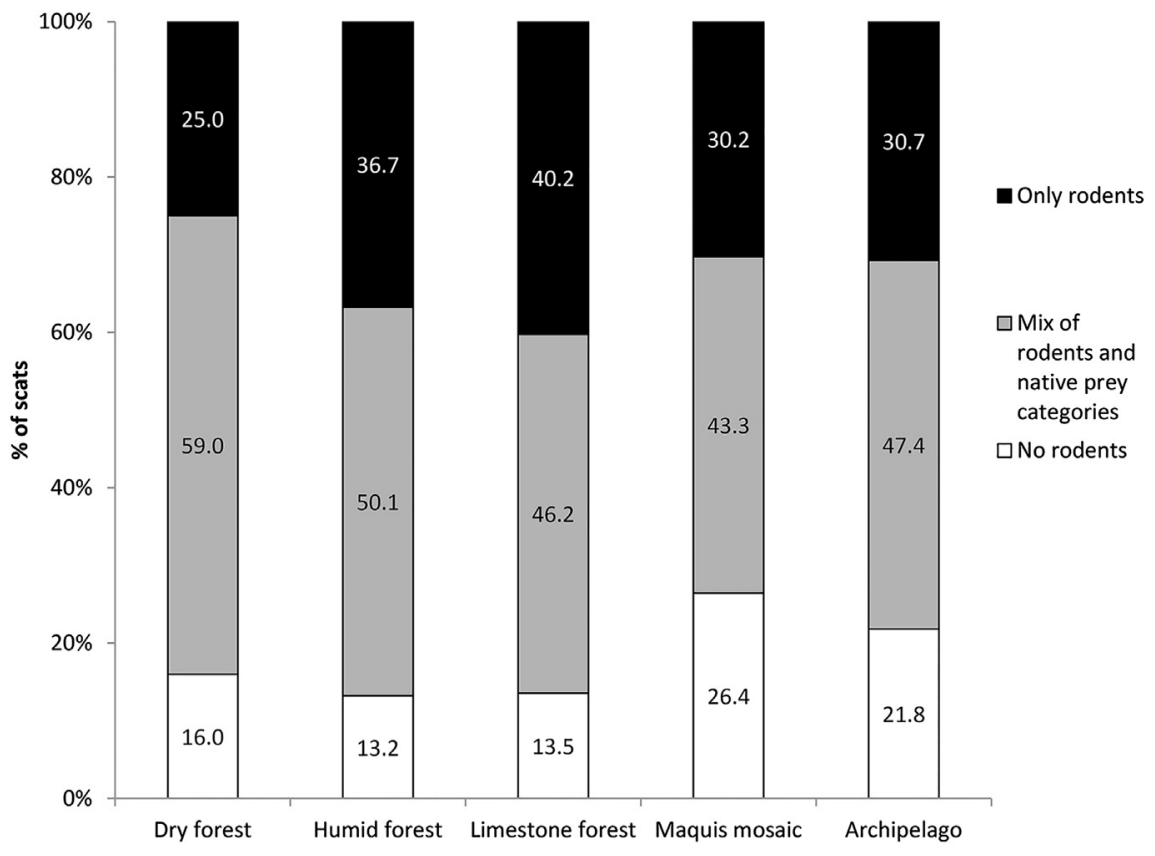

Fig. 2. Percentage of scats containing only rodent remains (black portion), no rodent remains but remains of the 4 other categories (white portion), a mix of both rodent remains and remains of at least 1 of the 4 other categories (grey portion).

Dry forest Humid forest Limestone forest Maquis mosaic Archipelago

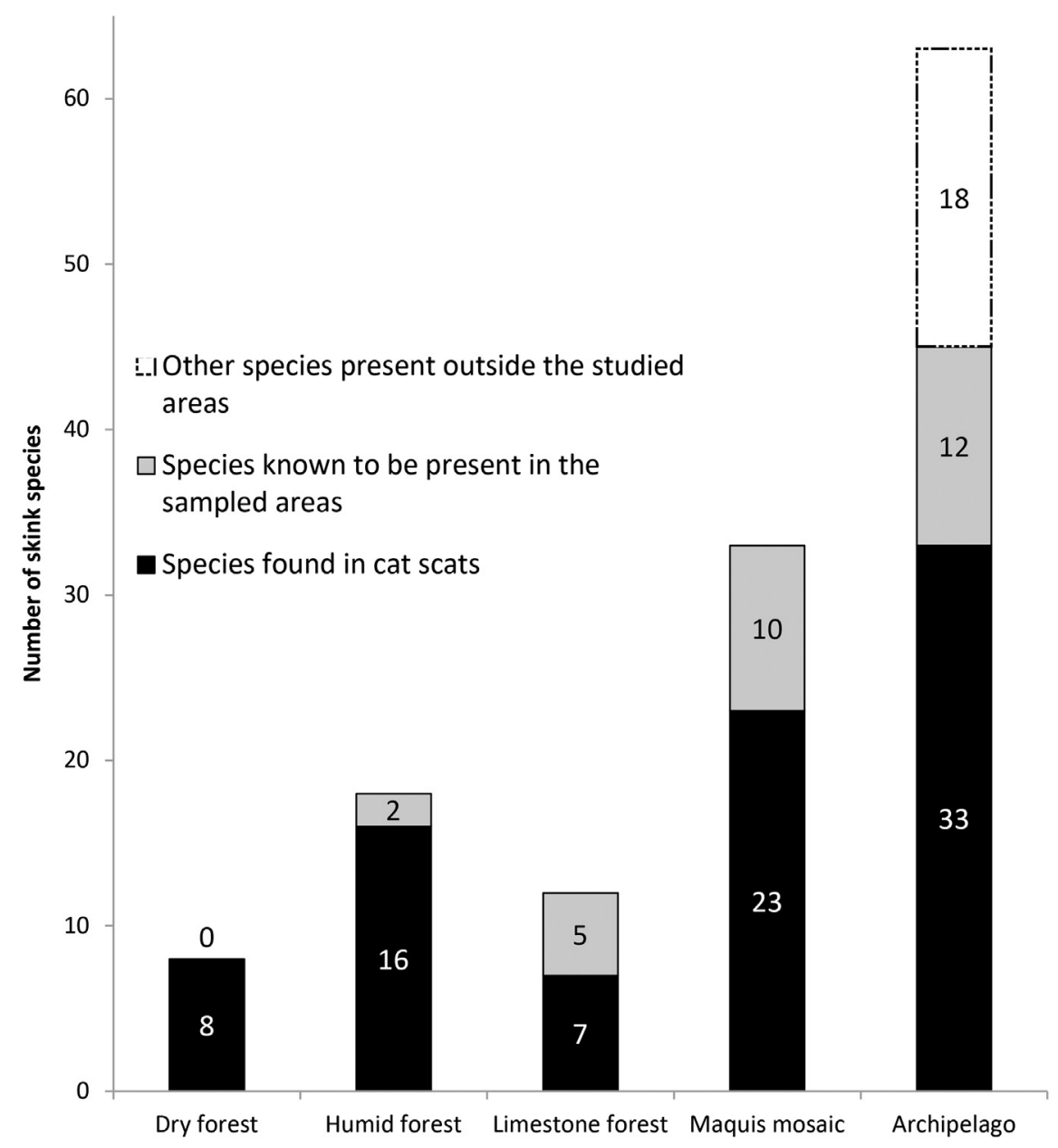

Fig. 3. Species found in cat scats (black portion), and known to be present in the sampled areas (grey portion), in the different studied habitats.

Conversely, gecko species were rarely found in the sampled cat scats, whatever the habitat and sampling period (mean $\mathrm{FO}=3 \%$ ) and only two genera were identified (out of 7 endemics).

Arthropods (mainly insects) frequently fell prey to feral cats in all habitats and all seasons. The effect of habitat was significant ( $\mathrm{P}<0.001$ ), the highest FO of arthropods in cat scats being found in the maquis mosaic $(41.0 \%)$ and the lowest being found in the humid forest $(15.8 \%)$. There was an effect of habitat*season $(\mathrm{P}<0.001)$, and 


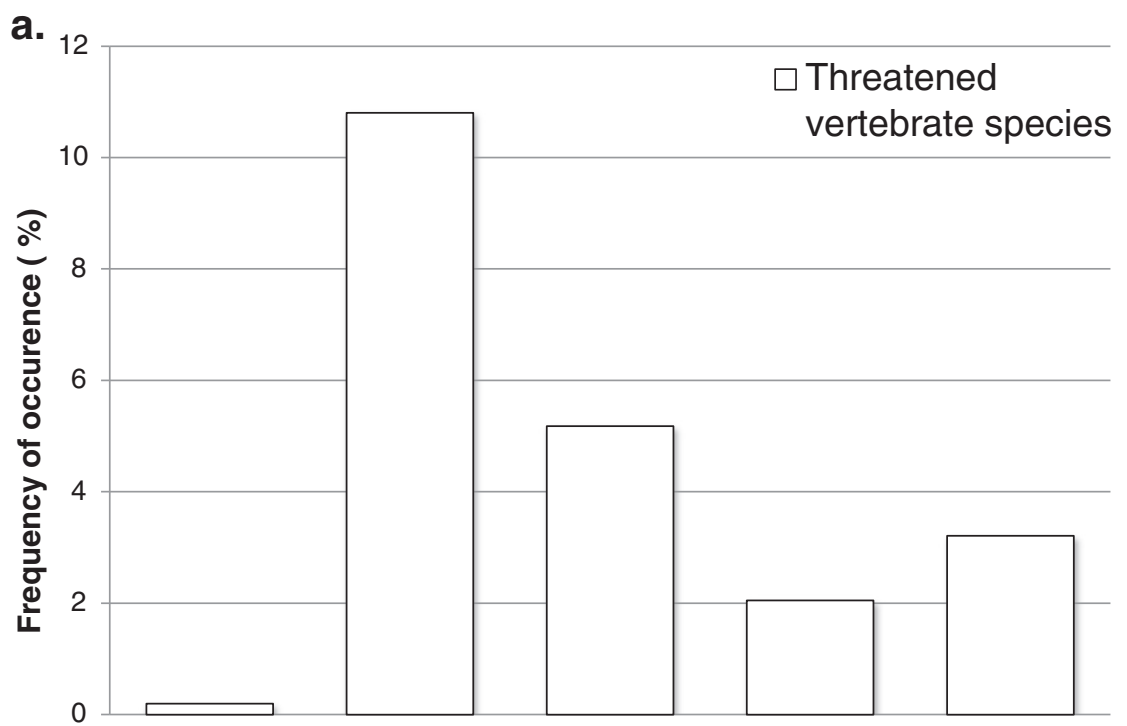

Fig. 4. Threatened vertebrate species preyed upon by feral cats in New Caledonia: a) Frequency of cat scats containing remains of at least one IUCN Red-listed species, b) Number of threatened species preyed upon by feral cats and their IUCN Red List status: "CR": Critically Endangered; "EN": Endangered; "VU": Vulnerable.

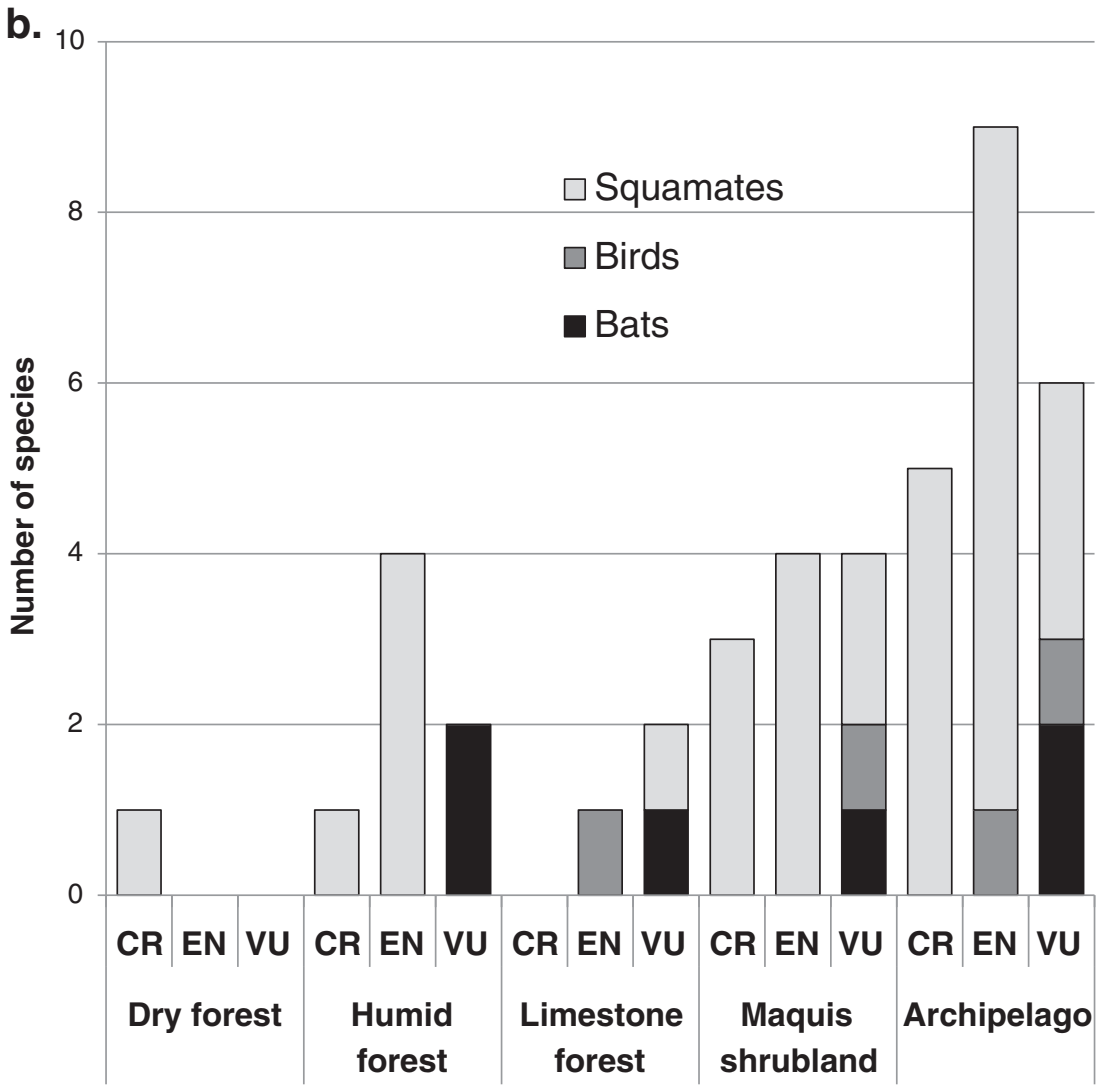

no effect of season on the FO of arthropods in cat diets $(\mathrm{P}=0.06)$.

The most frequent occurrence of threatened species remains in the cat diet was found in the humid forest $(\mathrm{FO}=10.8 \%$ ), with a significant effect of habitat $(\mathrm{P}<0.001)$. The seasonal effect was significant $(\mathrm{P}<0.01)$, the highest FO being found during the dry season $(3.76 \%)$. The GLM describing threatened species occurrence in cat diet correctly predicted presence and absence (AUC $=0.76$ ) (Table A.2).

We identified a minimum of 44 native vertebrate species in the diet of feral cats: 3 bat species, 6 bird species, 2 gecko species, and 33 skink species (Table A.1). They included 20 IUCN Red-listed threatened species ( 2 flying fox species, 16 skinks, 1 seabird, 1 parakeet), comprised of $5 \mathrm{CR}, 9 \mathrm{EN}$, and $6 \mathrm{VU}$ species (underlined in Table A.1), all strictly endemic at species level, except Gould's petrel (endemic at subspecies level). By habitat, the number of IUCN Red-listed threatened species predated by feral cats was 11 for the maquis mosaic, 7 for the humid forest, 3 for the limestone forest and 1 for the dry forest (Fig. 4).

\section{Discussion}

With 14 different study sites in the same biodiversity hotspot and $>5300$ scats collected and analyzed, this study constitutes, to the best of our knowledge, the largest original study devoted to feral cat diet analysis on islands to date. Although the abundance of cat scats and 
the sampling effort differed (Table 1), our extensive sampling showed that feral cats have invaded the whole archipelago and are present all year round even in the most remote habitats. No cat diet study had previously been conducted in New Caledonia, despite the fact that it hosts $>128$ endemic vertebrates, of which 82 are endangered species, and that most are known to be potential prey for cats. This study bridges a major gap by considering the feral cat diet at the scale of a whole biodiversity hotspot of prime importance in the tropical Pacific region.

\subsection{Overall cat diet}

As traces of anthropogenic refuse and/or industrial food were only found in $2.9 \%$ of cat scats, we assumed that most of our samples came from feral cats living independently of human feeding.

Rodent remains were found in $78.2 \%$ of feral cat scat samples. This abundant food resource can help sustain feral cat abundance at a high level, thereby exacerbating predation pressure on native wildlife via the "hyperpredation" process (Courchamp et al., 1999; Ringler et al., 2015). This result is consistent with the FO found by Bonnaud et al. (2011) $(44.05 \pm 28.3$, 55 studies) in their review of the cat diet on islands worldwide.

Apart from rodents that constituted the basis of cat diet in New Caledonia, we found that feral cats fed on a wide range of prey, from small insects to medium-sized birds and mammals (at least 44 species). This result is unsurprising, since feral cats are known to be highly generalist predators (e.g. Doherty et al., 2015a; Peck et al., 2008; Turner and Bateson, 2014). Interestingly, however, this study revealed some rather atypical patterns of predation on native, endemic and threatened species. Notably, we showed that squamates were the primary native prey category in cat diet $(42.8 \%$ and at least 35 species preyed). This result is consistent with the conclusion given by Bonnaud et al. (2011), showing a negative correlation between reptile consumption and latitude. In New Caledonia, squamates are preyed upon by cats at a higher rate (in FO) than in most islands worldwide, probably due to their high abundance and high species richness (Bauer et al., 2012a; Skipwith et al., 2016; Smith et al., 2007). For example, in Bonnaud et al. (2011) and Doherty et al. (2015a) squamates were found in $34.52 \pm 5.22 \%$ (15 studies) and in $24.00 \pm 3.03 \%$ (49 studies) of cat scats respectively. In addition, we observed that $32.5 \%$ of scats that contained squamate remains contained more than one individual (on average $1.61 \pm 1.45$ individuals minimum/scat and ranging between 1 and 29 individuals minimum/scat).

Surprisingly, geckos did not seem to feature in the feral cat diet (FO $=3 \%$ ) despite their high species richness and abundance in New Caledonia (Skipwith et al., 2016). However, most feral cat diet studies finding high FO of gecko remains were based on gut and stomach contents rather than scat analysis (e.g. Seabrook, 1990; Tidemann et al., 1994). It may be that gecko predation is underestimated in cat scat studies, since few gecko remains are identifiable once the entire digestion process is complete (Zarzoso-lacoste et al., 2016). This contrasts with skinks, whose scales are resistant to digestive transit and conserve most of their diagnostic characteristics (Jourdan et al., 2014).

Another noteworthy finding on feral cat impact in New Caledonia is the high level of predation on bats (mostly flying foxes) that occurred all year round. Substantial flying fox remains were found in the feral cat diet in three of the four study habitats and nine of the 14 sampling sites. The FO of flying fox remains was often high, with for example 13.1\% for one humid forest site. Cat predation on bats is only rarely or marginally reported in diet studies (e.g. Scrimgeour et al., 2012; Doherty et al., 2015a), and predation specifically on flying foxes, as far as we know, in only two studies (Tidemann et al., 1994; Christmas island Australia-predation event-; Vincenot et al., 2015, Japan-potential predation-). The consequences of such predation can be particularly harmful, as flying foxes (i) have few natural predators and consequently present naive behavior, and (ii) are long-lived species with particularly high adult mortality (Voigt and Kingston, 2016). The magnitude of this predation and its impact on flying fox population dynamics has yet to be explored.

The FO of bird remains in feral cat scats (18\%) was lower than those generally reported in other studies. Indeed, reviews by Bonnaud et al. (2011) and Doherty et al. (2015a) indicated an average FO for bird remains of respectively $31.93 \pm 2.85 \% \quad$ (41 studies) and $26.93 \pm 2.49 \%$ (49 studies). The seasonal pattern for cats' diet was mainly driven by a higher predation on birds during the wet season that is mainly linked with higher seabird presence during the breeding season that occurs between October and May for Ardenna pacifica (unpublished results) and Pterodroma leucoptera (Bretagnolle and Villard, 2007). When seabirds (petrels and shearwaters) were present at our study sites, predation by feral cats was particularly frequent (e.g. FO $38.3 \%$ for one of our maquis mosaic mountain sites), with seabirds the main secondary prey after introduced rodents (Keitt et al., 2002; Bonnaud et al., 2015). Tahiti and Gould's petrels were frequently found in the cat diet (FO of remains in cat scats sometimes exceeding 7.9\%), although colony locations and size and status of populations remain largely unknown. Cats are efficient predators that can kill both adults and chicks of most small or medium-sized species of seabirds. Procellariides' naive and clumsy behavior when on the ground makes them particularly vulnerable to introduced predators (Bourgeois and Vidal, 2008; Hilton and Cuthbert, 2010). Due to their long lifespans, low reproductive rates and delayed maturity, the population dynamics of these seabird species is particularly sensitive to adult mortality (e.g. Le Corre, 2008). The feral cat's impact on these seabirds simply adds to the other anthropogenic threats these species face, both on land (breeding habitat degradation due to mining activities, artificial light, other invasive predators, etc.) and at sea ('by-catches' in fishing operations, marine resource depletion, global change consequences, etc.) (e.g. Croxall et al., 2012).

Counter-intuitively, the analysis of 776 feral cat scats collected at two different sites harboring high Kagu densities did not reveal any predation on this endangered and iconic flightless New Caledonian bird. Feral cats have been directly responsible for the extinction of numerous bird species (e.g. Doherty et al., 2016b), especially small and medium-sized flightless island bird species, generally considered highly vulnerable to introduced alien predators (Roots, 2006). Although the Kagu is within the size and weight ranges of feral cat prey (Bonnaud et al., 2011), we hypothesize that the Kagu may have developed efficient defensive behavior (Hunt et al., 1996), which could explain why no cat predation was detected.

It was not possible to be as accurate in identifying arthropod prey species because of the high diversity of this group and taxonomic uncertainties. However, feral cats appear to have preyed upon a large range of arthropods, from small cicada to large crustaceans, with an overall mean FO of $35.2 \%$ comparable to the FO found by Doherty et al., 2015a (average FO for arthropods remains of $36.15 \pm 2.78 \%$ ). As shown in several studies (Bonnaud et al., 2011; Doherty et al., 2015a; Konecny, 1987; Medina and Garcia, 2007), insects were the main arthropod prey, especially Coleoptera, Orthoptera, Hemiptera, Hymenoptera and Phasmatodea. Arthropods are more preyed upon by cats during the wet season whatever the habitat, except for maquis mosaic habitat. However for maquis mosaic FOs of arthropods in cat diet were particularly high for both seasons compared with others studied habitats. As maquis mosaic habitat on ultramafic soils showed lower productivity and lower resources availability (Barré et al., 2010), especially during the dry season, cats switch to alternative and secondary resources resulting in higher predation on arthropods.

Genetic analysis of gut/scat contents (e.g. barcoding) would likely improve identification of the most cryptic prey and of prey groups, like geckos, with few identifiable post-digestion remains (Zarzoso-lacoste et al., 2016). It would also make it possible to distinguish between species indistinguishable by macroscopic analysis, such as Pterodroma leucoptera/ Pseudobulweria rostrata and Pteropus tonganus/Pteropus vetulus. 


\subsection{Unprecedented numbers of threatened species in cat diet}

Feral cats in New Caledonia were here shown to prey upon at least 20 IUCN globally threatened mammal (2), squamate (16) and bird (2) species. Bonnaud et al. (2011) and Doherty et al. (2015a) listed 29 and 16 IUCN threatened species predated by feral cats. While our sampling effort was extensive, this impact is even likely to have been underestimated: our geographic range did not cover the distribution areas of some highly restricted endemic species, yet feral cats appear to roam even in the most remote places.

Therefore this study adds at least $44 \%$ to the number of IUCN threatened species found in feral cat diet studies on islands (including Australia). It shows that New Caledonia hosts $30.8 \%$ of the IUCN threatened species revealed by diet studies of feral cats on the world's islands. Representing only $0.12 \%$ of the world's island land area, the New Caledonian archipelago is the smallest biodiversity hotspot on earth. The greatly underestimated impact it faces from feral cats is therefore unacknowledged and disproportionate. Although feral cats are known to be among the most damaging species introduced to islands (Doherty et al., 2016b), their global impact on insular fauna has so far been underestimated due to the lack of studies on islands with high biodiversity value. This intensive assessment of the feral cat threat to New Caledonian biodiversity argues strongly for investigating the feral cat diet and impacts on other islands that harbor high biodiversity and endemism rates but where there have been few or no investigations, especially in the Pacific: Polynesian, Micronesian and Melanesian islands (Bonnaud et al., 2011; Nogales et al., 2013).

\subsection{Conservation and management implications}

Feral cats are known to have contributed significantly to island vertebrate extinctions and declines worldwide (Doherty et al., 2016b; Medina et al., 2011; Woinarski et al., 2015). Understanding and reducing their impacts is thus considered essential for threatened and endemic species conservation; cat population management has generally involved reducing populations through lethal operations (Keitt et al., 2011; Russell et al., 2016). Effective feral cat management (especially eradications) on numerous islands generally has positive effects on native biodiversity conservation (e.g. Jones et al., 2016). Although recent actions succeeded in eradicating cats from large uninhabited islands (Dirk Hartog island: 62,000 ha, Marion island: 29,000 ha) (Campbell et al., 2011; Parkes et al., 2014), such an outcome is currently unachievable for even larger islands like the New Caledonian main island (1.66 million ha) and most of its principal satellite islands. Furthermore, the companion status of domestic cats, and the human presence on most New Caledonian islands, create additional constraints and obstacles for eradication or large-scale control of feral cats (e.g. Glen et al., 2013).

New Caledonia is a small, emancipated insular country with limited resources, not yet fully committed to and experienced in invasive predator management (Beauvais et al., 2006). However, an action plan is currently being drawn up by the local environmental authorities, and the results of this study prompted them to list feral cats among the topfive priority species for future management in New Caledonia. Given the limited resources available for conservation programs and the high costs associated with lethal control of invasive predators, we recommend that future actions be prioritized based on the urgency of conservation situations (most impacted and endangered native species). The first target should be geographical areas of manageable size already offering some management facilities and support (e.g. protected or managed natural areas with competent staff and conservation means). Our findings show that feral cats affect a wide range of threatened species in New Caledonia in various habitats. However, they indicate that cat predation upon IUCN-listed threatened species is more intensive and wide-ranging in maquis mosaic and humid forest habitats. Consequently, we recommend that feral cat management actions be conducted on sites key to threatened species conservation, i.e. in humid and maquis mosaic habitats, particularly areas with abundant flying-fox rookeries, petrel colonies and micro-endemic endangered squamate populations. As the maquis mosaic habitat is used extensively for mining activities (Pascal et al., 2008), such cat control programs could be implemented and funded under a biodiversity offsetting approach (Holmes et al., 2016).

We also recommend preventing cat arrival in the rare remaining areas not yet colonized, namely some isolated or near-shore islets (Doherty et al., 2016a), which often constitute unique refuges for endangered fauna. Other islets harboring small feral cat populations might also be good candidates for future, fairly straightforward eradication projects coupled with subsequent biosecurity measures.

In addition to 'classical' lethal actions (control or eradication), alternative management approaches recently developed elsewhere should be considered for inclusion in the New Caledonian feral cat management strategy currently being elaborated, especially exclusion fencing. Finally, cost-benefit analyses could go a long way towards optimizing management strategy and conservation gains from the actions to be implemented (Doherty and Ritchie, 2017).

\section{Acknowledgements}

This study was funded by the Province Nord (Contracts No. 12C240, 13C375, 14C330, 15C331), Province des îles (Contract No. 209/2014), Province Sud (Contracts No. C276-12, C283-12, C588-13), SLN Nickel (Contracts No. 11-171, DE2015-001), CNRT Nickel (Contract No. 08NRT.IRD/Rmine), CEN (Contract No. I345/2012/CEN). We are very grateful to civil and traditional customary authorities and landowners for allowing us to conduct this research in their respective areas, especially Parc Provincial de la Rivière Bleue, Parc des Grandes Fougères, Réserve Botanique de la chute de la Madeleine, Réserve Naturelle du Mont Panié, GDPL Bomene Tapu, île des Pins, Ouvéa, Lifou, Mine de Tiébaghi, Mine de Kopéto. We are also very grateful to Dayu Biik (Association pour la Conservation en co-gestion du Mont Panié), ASBO (Association pour la Sauvegarde de la Biodiversité d'Ouvéa) and numerous colleagues and students for providing invaluable support in fieldwork and sampling. We thank Marjorie Sweetko for improving the English of the manuscript.

\section{Role of the funding source}

Funding sources for this study were local public or private institutions in charge of environment and biodiversity in New Caledonia. Study sites selection was made jointly with these institutions, but funding sources have had no other role in the study design, sample analysis, interpretation of data or writing of the manuscript neither in the decision to submit it for publication.

\section{Appendix A. Supplementary data}

Supplementary methodology associated with this article can be found in the online version, at doi: http://dx.doi.org/10.1016/j.biocon. 2017.08.003. These appendices contain details of methods used to determine prey remains (Appendix 1), detailed descriptions of the 4 studied habitats (Appendix 2), detailed overall diet composition of Felis silvestris catus (Appendix 3), Generalized Linear Model (GLM) results and AUC values (Appendix 4), and Generalized Linear Model (GLM) parameters and results by modality for each effect (Appendix 5).

\section{References}

Barré, N., Hebert, O., Aublin, R., Spaggiari, J., Chartendrault, V., Baillon, N., Le Bouteiller, A., 2009. Troisième complément à la liste des oiseaux de NouvelleCalédonie. Alauda 77, 287-302.

Barré, N., Chazeau, J., Jourdan, H., 2010. La faune des milieux sur roches ultramafiques. 
In: L'Huilier, L., Jaffré, T., Wulff, A. (Eds.), Mines et Environnement en NouvelleCaledonie: les milieux sur substrats ultramafiques et leur restauration. Editions IAC, Nouméa, pp. 105-128.

Bauer, A.M., Jackman, T.R., Sadlier, R.A., Whitaker, A.H., 2012a. Revision of the giant geckos of New Caledonia (Reptilia: Diplodactylidae: Rhacodactylus). Zootaxa 3404, $1-52$.

Bauer, A.M., Sadlier, R.A., Jackman, T.R., Shea, G., 2012b. A new member of the Bavayia cyclura species group (Reptilia: Squamata: Diplodactylidae) from the southern ranges of New Caledonia. Pac. Sci. 66, 239-247. http://dx.doi.org/10.2984/66.2.10.

Beauvais, M.-L., Coléno, A., Jourdan, H., 2006. Invasive Species in the new Caledonian Archipelago: A Major Economic and Environmental Hazard. Collection Expertise Collégiale, IRD Editions, Paris, France, pp. 259.

Blackburn, T.M., Cassey, P., Duncan, R.P., Evans, K.L., Gaston, K.J., 2004. Avian extinction and mammalian introductions on oceanic islands. Science 305, 1955-1958. http://dx.doi.org/10.1126/science.1101617.

Bonnaud, E., Bourgeois, K., Vidal, E., Kayser, Y., Tranchant, Y., Legrand, J., 2007. Feeding ecology of a feral cat population on a small Mediterranean island. J. Mammal. 88, 1074-1081. http://dx.doi.org/10.1644/06-MAMM-A-031R2.1.

Bonnaud, E., Medina, F.M., Vidal, E., Nogales, M., Tershy, B., Zavaleta, E., Donlan, C.J., Keitt, B., 2011. The diet of feral cats on islands: a review and a call for more studies. Biol. Invasions 13, 581-603. http://dx.doi.org/10.1007/s10530-010-9851-3.

Bonnaud, E., Palmas, P., Bourgeois, K., Ollier, S., Zarzoso-Lacoste, D., Vidal, E., 2015. Island specificities matter: cat diet differs significantly between islands of a major breeding archipelago for a vulnerable endemic seabird. Biol. Invasions 17, 2927-2941. http://dx.doi.org/10.1007/s10530-015-0921-4.

Bourgeois, K., Vidal, E., 2008. The endemic Mediterranean yelkouan shearwater Puffinus yelkouan: distribution, threats and a plea for more data. Oryx 42, 187-194. http://dx. doi.org/10.1017/S0030605308006467.

Bretagnolle, V., Villard, P., 2007. Le Pétrel de la Chaîne Pterodroma (leucoptera?) caledonica, Synthèse des connaissances acquises entre 1994 et 2007. Unpublished report. Province Sud/Centre d'études Biologiques de Chizé (54p).

Campbell, K.J., Harper, G., Algar, D., Hanson, C.C., Keitt, B.S., Robinson, S., 2011. Review of feral cat eradications on islands. In: Veitch, C.R., Clout, M.N., Towns, D.R. (Eds.), Island Invasives: Eradication and Management. IUCN, Gland, Switzerland, pp. 37-46 (and Auckland, New Zealand: CBB).

Clavero, M., Garcia-Berthou, E., 2005. Invasive Species are a Leading Cause of Animal Extinctions. vol. 20. pp. 110. http://dx.doi.org/10.1016/j.tree.2005.01.003.

Courchamp, F., Langlais, M., Sugihara, G., 1999. Control of rabbits to protect island birds from cat predation. Biol. Conserv. 89, 219-225. http://dx.doi.org/10.1016/S00063207(98)00131-1.

Courchamp, F., Chapuis, J.-L., Pascal, M., 2003. Mammal invaders on islands: impact, control and control impact. Biol. Rev. Camb. Philos. Soc. 78, 347-383.

Croxall, J.P., Butchart, S.H.M., Lascelles, B.E.N., Stattersfield, A.J., Sullivan, B.E.N. Symes, A., Taylor, P., 2012. Seabird conservation status, threats and priority actions: a global assessment. Bird Conserv. Int. 22, 1-34.

Doherty, T.S., Ritchie, E.G., 2017. Stop jumping the gun: a call for evidence-based invasive predator management. Conserv. Lett. 10, 15-22. http://dx.doi.org/10.1111/ conl.12251.

Doherty, T.S., Davis, R.A., van Etten, E.J.B., Algar, D., Collier, N., Dickman, C.R., Edwards, G., Masters, P., Palmer, R., Robinson, S., 2015a. A continental-scale analysis of feral cat diet in Australia. J. Biogeogr. 42, 964-975. http://dx.doi.org/10.1111/ jbi.12469.

Doherty, T.S., Dickman, C.R., Nimmo, D.G., Ritchie, E.G., 2015b. Multiple threats, or multiplying the threats? Interactions between invasive predators and other ecological disturbances. Biol. Conserv. 190, 60-68. http://dx.doi.org/10.1016/j.biocon.2015. 05.013.

Doherty, T.S., Dickman, C.R., Johnson, C.N., Legge, S.M., Ritchie, E.G., Woinarski, J.C.Z., 2016a. Impacts and management of feral cats Felis catus in Australia. Mammal Rev. 1-15. http://dx.doi.org/10.1111/mam.12080.

Doherty, T.S., Glen, A.S., Nimmo, D.G., Ritchie, E.G., Dickman, C.R., 2016b. Invasive predators and global biodiversity loss. Proc. Natl. Acad. Sci. 113, 11261-11265. http://dx.doi.org/10.1073/pnas.1602480113.

Driscoll, C.A., Menotti-Raymond, M., Roca, A.L., Hupe, K., Johnson, W.E., Geffen, E., Harley, E.H., Delibes, M., Pontier, D., Kitchener, A.C., Yamaguchi, N., O'brien, S.J., Macdonald, D.W., 2007. The near eastern origin of cat domestication. Science 317, 519-523. http://dx.doi.org/10.1126/science.1139518.

Dubois, J., Guillon, J.H., Launay, J., Recy, J., Trescases, J.J., 1973. In: Coleman, P.J. (Ed.), The Western Pacific: Island Arcs, Marginal Seas, Geochemistry. University of Western Australia Press, Perth, pp. 223-235.

Fawcett, T., 2006. An introduction to ROC analysis. Pattern Recogn. Lett. 27, 861-874. http://dx.doi.org/10.1016/j.patrec.2005.10.010.

Fielding, A.H., Bell, J.F., 1997. A review of methods for the assessment of prediction errors in conservation presence/absence models. Environ. Conserv. 24, 38-49.

Glen, A.S., Pech, R.P., Byrom, A.E., 2013. Connectivity and invasive species management: towards an integrated landscape approach. Biol. Invasions 15, 2127-2138. http://dx. doi.org/10.1007/s10530-013-0439-6.

Grandcolas, P., Murienne, J., Robillard, T., Desutter-Grandcolas, L., Jourdan, H., Guilbert, E., Deharveng, L., 2008. New Caledonia: a very old Darwinian island? Philos. Trans. R. Soc. Lond. Ser. B Biol. Sci. 363, 3309-3317. http://dx.doi.org/10.1098/rstb.2008. 0122 .

Hand, S.J., Grant-mackie, J.A., 2011. Late-Holocene bats of Mé Auré Cave, New Caledonia: evidence of human consumption and a new species record from the recent past. The Holocene 22, 79-90. http://dx.doi.org/10.1177/0959683611409783.

Hilmer, S.S., Algar, D., Johnston, M., 2010. Opportunistic observation of predation of Loggerhead turtle hatchlings by feral cats on Dirk Hartog Island, Western Australia. J. R. Soc. West. Aust. 93, 141-146.
Hilton, G.M., Cuthbert, R., 2010. The catastrophic impact of invasive mammalian predators on birds of the UK Overseas Territories: a review and synthesis. Ibis 152, 443-458. http://dx.doi.org/10.1111/j.1474-919X.2010.01031.x.

Holmes, N.D., Howald, G.R., Wegmann, A.S., Donlan, C.J., Finkelstein, M., Keitt, B., 2016. The potential for biodiversity offsetting to fund invasive species eradications on islands. Conserv. Biol. 30, 425-427. http://dx.doi.org/10.1111/cobi.12641.

Hu, Y., Hu, S., Wang, W., Wu, X., Marshall, F.B., Chen, X., Hou, L., 2014. Earliest evidence for commensal processes of cat domestication. Proc. Natl. Acad. Sci. 111, 116-120. http://dx.doi.org/10.1073/pnas.1311439110.

Hunt, G.R., Hay, R., Veltman, C.J., 1996. Multiple Kagu Rhynochetos jubatus deaths caused by dog attacks at a high-altitude study site on Pic Ningua, New Caledonia. Bird Conserv. Int. 6, 295-306. http://dx.doi.org/10.1017/S0959270900001775.

Isnard, S., L'huillier, L., Rigault, F., Jaffré, T., 2016. How did the ultramafic soils shape the flora of the New Caledonian hotspot? Plant Soil 403, 53-76. http://dx.doi.org/10. 1007/s11104-016-2910-5.

IUCN, 2016. The IUCN Red List of Threatened Species. Version 2016-3. http://www. iucnredlist.org (Downloaded on 07 December 2016).

Jones, H.P., Holmes, N.D., Butchart, S.H., Tershy, B.R., Kappes, P.J., Corkery, I., AguirreMuñoz, A., Armstrong, D.P., Bonnaud, E., Burbidge, A.A., Campbell, K., 2016. Invasive mammal eradication on islands results in substantial conservation gains. Proc. Natl. Acad. Sci. 113, 4033-4038.

Jourdan, H., Brescia, F., Vidal, E., 2014. Impact des espèces invasives sur les reptiles des massifs miniers. In: Scientific Report CNRT/IRD/IAC, (91 pp.).

Keitt, B.S., Wilcox, C., Tershy, B.R., Croll, D.a., Donlan, C.J., 2002. The effect of feral cats on the population viability of black-vented shearwaters (Puffinus opisthomelas) on Natividad Island, Mexico. Anim. Conserv. 5, 217-223. http://dx.doi.org/10.1017/ S1367943002002263.

Keitt, B., Campbell, K., Saunders, A., Clout, M., Wang, Y., Heinz, R., Newton, K., Tershy, B., 2011. The global islands invasive vertebrate eradication database: a tool to improve and facilitate restoration of island ecosystems. In: Veitch, C.R., Clout, M.N., Towns, D.R. (Eds.), Island Invasives: Eradication and Management. International Union for Conservation of Nature, pp. 74-77.

Konecny, M.J., 1987. Food habits and energetics of feral house cats in the Galápagos Islands food habits and energetics of feral house cats in the Galapagos Islands. Oikos 50, 24-32.

Le Corre, M., 2008. Conservation biology: cats, rats and seabirds. Nature 451, 134-135.

Medina, E.M., Garcia, R., 2007. Predation of insects by feral cats (Felis silvestris catus L., 1758) on an oceanic island (La Palma, Canary Islands). J. Insect Conserv. 11, 203-207.

Medina, F.M., Bonnaud, E., Vidal, E., Tershy, B.R., Zavaleta, E.S., Josh Donlan, C., Keitt, B.S., Corre, M., Horwath, S.V., Nogales, M., 2011. A global review of the impacts of invasive cats on island endangered vertebrates. Glob. Chang. Biol. 17, 3503-3510. http://dx.doi.org/10.1111/j.1365-2486.2011.02464.x.

Mittermeier, R.A., Turner, W., Larsen, F., Brooks, T., Gascon, C., 2011. In: Zachos, F.E., Habel, J.C. (Eds.), Global Biodiversity Conservation: The Critical Role of Hotspots. Biodiversity Hotspots, Berlin, Germany, pp. 3-22.

Myers, N., Mittermeier, R.A., Mittermeier, C.G., Da Fonseca, G.A.B., Kent, J., 2000. Biodiversity hotspots for conservation priorities. Nature 403, 853-858.

Nogales, M., Vidal, E., Medina, F.M., Bonnaud, E., Tershy, B.R., Campbell, K.J., Zavaleta, E.S., 2013. Feral cats and biodiversity conservation: the urgent prioritization of island management. Bioscience 63, 804-810.

Parkes, J., Fisher, P., Robinson, S., Aguirre-Muñoz, A., 2014. Eradication of feral cats from large islands: an assessment of the effort required for success. N. Z. J. Ecol. 38, 307-314.

Pascal, M., Barré, N., de Garine-Wichatitsky, M., Lorvelec, O., Frétey, T., Brescia, F., Jourdan, H., 2006. Les peuplements néo-calédoniens de vertébrés: invasions, disparitions. In: Beauvais, M.L., Coléno, A., Jourdan, A. (Eds.), Les espèces envahissantes dans l'archipel néo-calédonien. IRD Éditions (collection Expertise Collégiale), Paris, pp. 111-162 ((coords):).

Pascal, M., Forges, B.R.D.E., Le Guyader, H., Simberloff, D., 2008. Mining and other threats to the New Caledonia biodiversity hotspot. Conserv. Biol. 22, 498-499. http://dx.doi.org/10.1111/j.1523-1739.2008.00889.x.

Peck, D.R., Faulquier, L., Pinet, P., Jaquemet, S., Corre, M. Le, 2008. Feral cat diet and impact on sooty terns at Juan de Nova Island, Mozambique Channel. Anim. Conserv. 11, 65-74. http://dx.doi.org/10.1111/j.1469-1795.2007.00153.x.

R Core Team, 2014. R: A language and environment for statistical computing. R Foundation for Statistical Computing, Vienna, Austria. http://www.R-project.org/.

Recio, M.R., Seddon, P.J., Moore, A.B., 2015. Niche and movement models identify corridors of introduced feral cats infringing ecologically sensitive areas in New Zealand. Biol. Conserv. 192, 48-56. http://dx.doi.org/10.1016/j.biocon.2015.09. 004.

Ringler, D., Russell, J.C., Le Corre, M., 2015. Trophic roles of black rats and seabird impacts on tropical islands: mesopredator release or hyperpredation? Biol. Conserv. 185, 75-84. http://dx.doi.org/10.1016/j.biocon.2014.12.014.

Roots, C., 2006. Flightless Birds. Greenwood Press, Westport, Conn (235 pp.).

Russell, J.C., Jones, H.P., Armstrong, D.P., et al., 2016. Importance of lethal control of invasive predators for island conservation. Conserv. Biol. 30, 670-672. http://dx.doi. org/10.1111/cobi12666.

Sadlier, R.A., Whitaker, T., Wood, P.L., Bauer, A.M., 2012. A new species of scincid lizard in the genus Caledoniscincus (Reptilia: Scincidae) from northwest New Caledonia. Zootaxa 3229, 47-57.

Sadlier, R.A., Bauer, A.M., Wood, P.L.J., Smith, S.A., Jackman, T.R., 2013. A new species of lizard in the genus Caledoniscincus (Reptilia: Scincidae) from southern New Caledonia and a review of Caledoniscincus atropunctatus (Roux). Zootaxa 3694, 501-524. http://dx.doi.org/10.2984/1534-6188(2008)62[247:ANSSOB]2.0.CO;2.

Sadlier, R.A., Bauer, A.M., Smith, S.A., Shea, G.M., Whitaker, A.H., 2014a. High elevation 
endemism on New Caledonia's ultramafic peaks - a new genus and two new species of scincid lizard. Mém. Mus. Natl. Hist. Nat. 206, 115-125.

Sadlier, R.A., Shea, G.M., Jourdan, H., Whitaker, A.H., Bauer, A.M., 2014b. The New Caledonian leopard skink Lacertoides pardalis (Reptilia: Scincidae); a review of the species' morphology, distribution, behavior and conservation. Mém. Mus. Natl. Hist. Nat. 206, 31-44.

Sadlier, R.A., Bauer, A.M., Wood, P.L.J., Smith, S.A., Whitaker, A.H., Jackman, T.R., 2014c. Cryptic speciation in the New Caledonian lizard genus Nannoscincus (Reptilia: Scincidae) including the description of a new species and recognition of Nannoscincus fuscus Günther. Mém. Mus. Natl. Hist. Nat. 206, 45-68.

Sadlier, R.A., Bauer, A.M., Wood, P.L.J., Smith, S.A., Whitaker, A.H., Jourdan, H., Jackman, T.R., 2014d. Localized endemism in the southern ultramafic bio-region of New Caledonia as evidenced by the lizards in the genus Sigaloseps (Reptilia: Scincidae), with descriptions of four new species. Mém. Mus. Natl. Hist. Nat. 206, 13-30.

Sax, D., Gaines, S., 2008. Species invasions and extinction: the future of native biodiversity on islands. Proc. Natl. Acad. Sci. 105, 11490-11497.

Scrimgeour, J., Beath, A., Swanney, M., 2012. Cat predation of short-tailed bats (Mystacina tuberculata rhyocobia) in Rangataua Forest, Mount Ruapehu, Central North Island. New Zeal. J. Zool. 39, 257-260. http://dx.doi.org/10.1080/03014223.2011. 649770.

Seabrook, W., 1990. The impact of the feral cat (Felis catus) on the native fauna of Aldabra Atoll, Seychelles [Indian Ocean]. Rev. Ecol. (Terre Vie) 45, 135-146.

Skipwith, P.L., Bauer, A.M., Jackman, T.R., Sadlier, R.A., 2016. Old but not ancient: coalescent species tree of New Caledonian geckos reveals recent post-inundation diversification. J. Biogeogr. 43, 1266-1276. http://dx.doi.org/10.1111/jbi.12719.
Smith, S.A., Sadlier, R.A., Bauer, A.M., Austin, C.C., Jackman, T., 2007. Molecular phylogeny of the scincid lizards of New Caledonia and adjacent areas: evidence for a single origin of the endemic skinks of Tasmantis. Mol. Phylogenet. Evol. 43, 1151-1166. http://dx.doi.org/10.1016/j.ympev.2007.02.007.

Tershy, B.R., Shen, K.-W., Newton, K.M., Holmes, N.D., Croll, D.A., 2015. The importance of islands for the protection of biological and linguistic diversity. Bioscience 75, 592-597. http://dx.doi.org/10.1093/biosci/biv031.

Tidemann, C.R., Yorkston, H.D., Russack, A.J., 1994. The diet of cats, Felis catus, on Christmas Island, Indian Ocean. Wildl. Res. 21, 279-286. http://dx.doi.org/10.1071/ WR9940279.

Turner, D.C., Bateson, P.P.G. (Eds.), 2014. The Domestic Cat: The Biology of Its Behaviour, 3rd edn. Cambridge University Press, Cambridge (279 pp.).

Vincenot, C.E., Koyama, L., Russo, D., 2015. Near threatened? First report of unsuspected human-driven decline factors in the Ryukyu flying fox (Pteropus dasymallus) in Japan. Mamm. Biol. 80, 273-277. http://dx.doi.org/10.1016/j.mambio.2015.03.003.

Voigt, C.C., Kingston, T., 2016. Bats in the Anthropocene: Conservation of Bats in a Changing World. Springer, Cham Heidelberg.

Whitaker, A.H., Sadlier, R.A., 2011. Skinks and geckos from New Caledonia. The IUCN Red List of Threatened Species. Version 2016-3. www.iucnredlist.org.

Woinarski, J.C.Z., Burbidge, A.A., Harrison, P.L., 2015. Ongoing unraveling of a continental fauna: decline and extinction of Australian mammals since European settlement. Proc. Natl. Acad. Sci. 112, 4531-4540.

Zarzoso-lacoste, D., Bonnaud, E., Corse, E., Gilles, A., Meglecz, E., Costedoat, C., Gouni, A., Vidal, E., 2016. Improving morphological diet studies with molecular ecology: an application for invasive mammal predation on island birds. Biol. Conserv. 193, 134-142. http://dx.doi.org/10.1016/j.biocon.2015.11.018. 